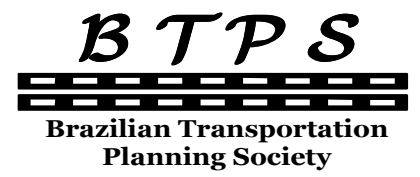

Journal of Transport Literature

Vol. 8, n. 2, pp. 38-72, Apr. 2014

Research Directory

\title{
Measurement of a cost function for US airlines: restricted and unrestricted translog models
}

[Mensuração de uma função de custo para companhias aéreas norte-americanas: modelos translog restritos e irrestritos]

\author{
William J. Meland* \\ University of Minnesota - United States
}

Submitted 7 Jan 2013; received in revised form 28 Mar 2013; accepted 16 Jun 2013

\begin{abstract}
This paper continues and expands several themes from previous studies of commercial airline cost functions. A well specified industrial cost function reveals characteristics about the market players, such as economies of scale and the cost elasticities with respect to operational styles. Using a translog specification, and its restricted first-order form, this paper updates previous parameter estimates, reworks the experimental design, and gives new analysis to describe the spectrum of choices facing airline firms in recent years. The translog model in this paper allows the energy cost share to interact with other variables and illuminate what factors may exacerbate cost sensitivity to energy prices, an advance in this specific area of interpretation. The result shows that fuel cost shares tend to be higher with older equipment, smaller fleet sizes, and to be increasing in aircraft size and seating density. The restricted first-order model indicates that older aircraft designs are more costly to operate, even accounting for operational style. This may imply that airlines with poorer access to capital suffer a cost disadvantage, particularly during a fuel spike - also a new contribution of the paper. Finally, the first-order model does not reject constant returns to scale (CRS) for fleet expansion, or increasing returns to scale (IRS) in aircraft size, which are the expected results.
\end{abstract}

Key words: airline cost function, translog model, econometric models.

\section{Resumo}

Este trabalho continua e estende vários temas de estudos anteriores de funções de custo de companhias aéreas comerciais. Uma função de custo industrial bem especificada revela características sobre os participantes de mercado, tais como economias de escala e as elasticidades de custo relativas a características operacionais. Usando uma especificação translog e sua forma restrita de primeira ordem, este artigo atualiza as estimativas anteriores da literatura, retrabalha o projeto do experimento, e proporciona uma nova análise para descrever o espectro de escolhas pelas quais as empresas aéreas vem enfrentando nos últimos anos. 0 modelo translog neste artigo possibilita que a participação dos custos de combustível nos custos totais seja interagida com outras variáveis, permitindo um esclarecimento dos fatores que podem agravar a sensibilidade dos custos aos preços do combustível - um avanço nesta área específica de interpretação. 0 resultado mostra que as participações de custos do combustível tendem a ser maiores com equipamentos mais antigos, com frotas menores, e tendem a ser crescentes com o tamanho e densidade de assentos das aeronaves. 0 modelo restrito de primeira ordem indica que aeronaves mais antigas possuem operações mais custosa, mesmo levando em consideração o estilo operacional da empresa. Isto pode implicar que as companhias aéreas com menos acesso ao capital sofrem uma desvantagem de custos, particularmente durante um pico de preços de combustível - o que também constitui uma contribuição do artigo. Finalmente, o modelo de primeira ordem não rejeita a hipótese de retornos constantes de escala para a expansão da frota, ou retornos crescentes com o tamanho das aeronaves, que são os resultados esperados.

Palavras-Chave: função de custo de companhia aérea, modelo translog, modelos econométricos.

*Email: wmeland@gmail.com.

\section{Recommended Citation}

Meland, W. J. (2014) Measurement of a cost function for US airlines: restricted and unrestricted translog models. Journal of Transport Literature, vol. 8, n. 2, pp. 38-72.

- JTL/RELIT is a fully electronic, peer-reviewed, open access, international journal focused on emerging transport markets and published by BPTS - Brazilian Transport Planning Society. Website www.transport-literature.org. ISSN 2238-1031. 


\section{Introduction}

This paper updates prior literature by calibrating a translog cost function of US airlines for recent years, using an engineering-centric, fleet-based approach. All costs are modeled at the fleet by fleet. Fortunately, data sources exist for these fleet-level costs. Other parameters are specified to help control for operational style: average flight stage length, seats per aircraft, fleet count, number of airports served by the fleet and airline, etc. By doing this, coefficients in the results should effectively model cost impacts of marginal changes in fleet characteristics - adding seats, flying longer distances, or employing older or newer equipment. Throughout, the aim is to produce a model sufficiently disaggregated that it could be used to model the cost of realistic operational changes, acknowledging that cost centers of aircraft fleets can be quite independent of others within the same firm.

Historically, the cost function has been important because it can reveal to us nearly everything about the production technology (Chambers, 1988). Here, by examining and modeling public data, we can explain how airline firms convert inputs into outputs. We can then identify whether the efficiency of firms appears to increase with scale. The effects of various external shocks - elevating the price of oil, for example - can be seen in the model outputs. The distinctions between indirect and direct costs; returns to scale; returns to scope; and fixed effects modeling are analyzed here with respect to earlier studies.

Understanding the cost functions for airlines, or their revenue functions, can yield helpful insights into transportation policy and/or general industrial forecasting. The most remarkable elements of this industry, perhaps inspiring past researchers, are (1) the contestability and commodification of players, implying efficiency; and (2) centrally collected data whose accuracy is overseen by a regulator.

Each major US airline collects and reports many categories of quarterly cost and operational data at the fleet level to federal regulators. This gives researchers great flexibility to test different models. Thanks to "Form 41" data, airlines can be seen as a transparent laboratory where firms act out strategies in a "natural" setting, governed by their own cost and revenue functions, while highly visible to researchers. 
Competitively, a "settling out" process has been in progress since formal US air market deregulation in 1978. That implies that the domestic market is fairly "contestable." If so, a single cost function could be applied across all companies in the market, representing "state of the art" production technology. This paper proceeds (as others have) with the assumption that one cost model generally applies.

I first construct a cost function for recent data using methods similar to Caves, Christensen and Tretheway (1984). In the full translog result, I find that elasticity of total cost with respect to fuel price (equivalently, fuel's cost share) tends to be higher with older equipment, and also with smaller fleet sizes. Also, cost elasticity with respect to fuel price tends to be increasing in aircraft size and seating density. Old aircraft technology, itself, appears to cause higher costs in the restricted first-order translog model

The sections of the paper proceed as follows: 1. Literature Review; 2. Model Specification; 3. Data and Empirical Strategy; 4. Estimation Results; Conclusion.

\section{Literature Review}

\subsection{Rationale of the Model: Contestability}

The validity of a nationwide cost model has been approached with practicality by a number of authors. While we can measure firm operations, and fix identity labels to their data, it is unclear whether the coefficients have a direct application in the industry. Previous authors have implied that firms are subject to a common set of institutions, markets, technology and the laws of physics. It is important to assert that competition does prevail, rather than some arbitrary uncompetitive space in which costs are not necessarily relevant, such as expense preference behavior in the regulated, as mentioned by Sickles (1986). It is most often claimed that the markets are contestable between the players whose costs we are attempting to fit into the common model.

A perfectly contestable market is defined as "one into which entry is completely free, from which exit is costless, in which entrants and incumbents compete on completely symmetric terms, and entry is not impeded by fear of retaliatory price alterations" (Baumol, Panzar, 1982). Can the industry in question satisfy this definition? The verdicts from various authors 
have been mixed. I assume that the production in this study takes place in a contestable fashion. Hence, a general set of cost elasticities (and cross-elasticities) are obtained and reported from all firms, although the cost intercepts are unique by firm. Adoption of contestable markets is an essential ingredient to a cost study.

\subsection{Cost Model Specification Literature - Cost Model Theory}

A theoretically valid cost function must exhibit certain properties (Varian, 1984). In particular, the cost function should be:

- non-decreasing in input factor prices and output quantities;

- homogeneous of degree one in factor prices;

- concave in factor prices; and

- continuously differentiable (ideally, twice differentiable) in prices.

Also, there should be zero fixed costs, and fulfillment of Shephard's Lemma,

such that:

$$
\frac{d T C(w, y)}{d w_{i}}=x_{i}
$$

with $w_{i}$ input prices and $x_{i}$ input quantities.

The properties of a valid cost function are discussed in Chambers, 1984.

\subsection{Cost Model Specification Literature - Engineering Based / Micro Models}

Swan (2006) builds a simulation of generic airline production costs at the micro level. This idea suggests a way to achieve the aim of the present work: to model actual airline cost data at the micro level. The operational cost function for aircraft is described by Swan as a model based solely on seat counts and flight distances. Swan's model takes the form:

$$
\ln (\text { cost })=A+B^{*} \ln (\text { seats })+C^{*} \ln (\text { distance })
$$


Other factors could be considered endogenous - and assuming CRS in fleet size, scale could be irrelevant as well. While we lack sufficient data resolution to use this model exactly, it is important to recognize that disaggregation has its benefits.

Aircraft ownership costs (and maintenance costs) are very real, but may reasonably be discarded in group analysis. Swan argues that costs may equilibrate and be discarded, as "the driver of used airplane values is the need to establish a cost position along the cost frontier... the cost frontier itself is designated by the price of newly manufactured airplanes." This cost frontier could be construed as an operational indifference curve, over which profitability is equal; thus, equipment costs could drop out. ${ }^{1}$

Morrison (1984) looks more deeply at the relationship between aircraft capital cost and the inherent efficiency of an aircraft's design. Uniform physical principles may underlie a significant portion of airline cost functions. The laws of physics, with their limitations of speed, reliability and fuel efficiency, affect aircraft operators uniformly in such a model, with respect to the equipment they choose. Firm equipment factor demands have a point of interface in the aircraft exchange market. As prices prevail along a cost frontier, differences that we observe can be assigned to coefficients in a fixed-factor or fixed-effects model.

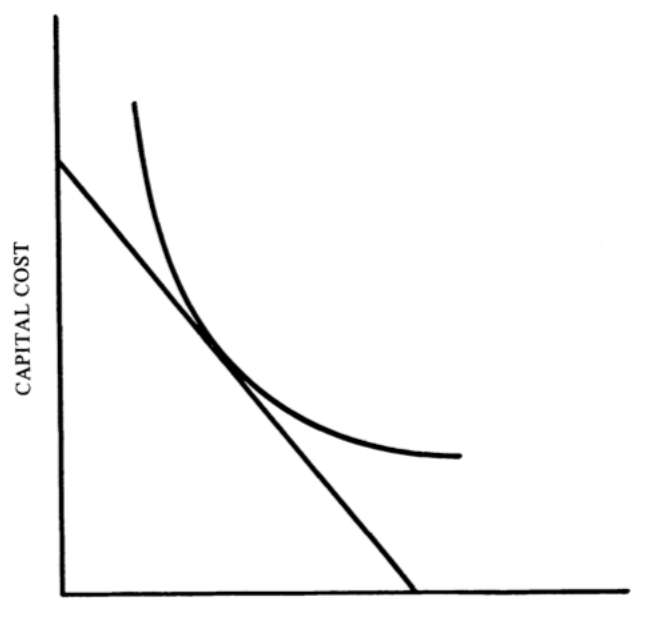

OPERATING COST PER MILE

Figure 1 - Capital Operating Efficiency vs. $\operatorname{Cost}^{2}$

\footnotetext{
${ }^{1}$ The assumption here by Swan is that a sufficiently liquid exchange market exists for used aircraft. It follows that the marginal profitability for such aircraft should be equal among firms, equalizing their lease values.

${ }^{2}$ Source: Morrison (1984), p. 136. Courtesy Brookings Papers.
} 
In Morrison's graphic, a frontier exists between capital costs and operating costs per mile (capital cost of aircraft versus its energy efficiency and maintenance costs). If such a frontier is monotonic, and exchange markets are liquid, then each firm chooses aircraft at its preferred location along that frontier, assuming all players are efficient. Like firms would choose like equipment, at like prices. An airline might wish to buy a more expensive aircraft with lower fuel consumption to provide a cushion against cost volatility of future fuel price spikes. Concerns about capital shortages, meanwhile, may encourage hoarding of cash and depress demand for new equipment temporarily.

These firm heterogeneity scenarios are each precluded by Morrison's assumption of a single frontier. Using the liquidity of aircraft purchasing and leasing, we are left with an operational cost solely determined by output, exclusive of aircraft cost, which is also the method suggested by Swan. This would perhaps rationalize new aircraft purchases at the firm level, a key point for Swan's employer, the Boeing Corporation, (as such purchases could be described as cost neutral).

The feature that distinguishes the "engineering-based" approach to econometric analysis is the analysis of a specific group of machines whose production process can be usefully understood by a single unit of production data. This disaggregated analysis comes closer to a "mechanical" functional form that is amenable to forecasting or static interpretation. To report only on aggregates of machines, while it can be interpreted observationally, has limited practicality in decision-making. Practical validity is enhanced if we have an accurate model of the micro production choices, as they exist, because this clears away aggregation bias. That issue is discussed directly in 1.7, and the proposed remedy in 2.3 .

\subsection{Cost Model Specification Literature - Panel Data of Firm Operations}

Caves, Christensen and Tretheway (1984) (hereafter CCT) is the main precursor of this study. $\mathrm{CCT}$ use scale and density coefficients to obtain the returns to scale (RTS) and returns to density (RTD). Their treatment of production "density" (or, increased product per geographical area) gives a fine substitute for scale itself within a geographic system. CCT use the first-order coefficients of a translog for their cost model (omitting the second-order components of the translog): 
$\ln [$ Total Cost $]=\beta_{0}+\beta_{1} \ln [$ Aircraft Miles $]+\beta_{2} \ln [$ points served $]+$

$\beta_{4} \ln [$ mean flight distance $]+\beta_{5}[$ load factor $]+\beta_{6}[$ labor price $]+$

$\beta_{7}[$ fuel price $]+\beta_{8}[$ capital-materials price $]+\beta_{8}[$ capacity $]+$

$\beta_{i}[$ firm identities $]$.

Expressed symbolically, CCT did a first-order restricted translog regression:

$$
\ln [\text { Total Cost }]=\alpha_{0}+\alpha_{Y} \ln Y+\sum_{i} \beta_{i} \ln W_{i}+\sum_{i} \phi_{i} \ln Z_{i}+\sum_{\text {Times }} \alpha_{T} \sum_{\text {Firms }} \alpha_{F}
$$

Where $Y$ is output, $W i$ are input prices, and the $Z_{i}$ are operational control variables that describe airline characteristics, or production styles. The coefficients on $\ln Z_{i}$ can give us cost elasticities of these characteristics.

CCT also performed both a full translog model:

$$
\begin{aligned}
& \operatorname{Ln}[\text { TotalCost }]= \\
& \alpha_{0}+\alpha_{Y} \ln Y+\sum_{i} \beta_{i} \ln W_{i}+\sum_{i} \phi_{i} \ln Z_{i}+1 / 2 \delta_{Y Y}(\ln Y)^{2} \\
& +1 / 2 \sum_{i} \sum_{j} \gamma_{i j} \ln W_{i} \ln W_{j}+1 / 2 \sum_{i} \sum_{j} \psi_{i j} \ln Z_{i} \ln Z_{j} \\
& +\sum_{i} \rho_{Y_{i}} \ln Y \ln W_{i}+\sum_{i} \mu_{Y_{i}} \ln Y \ln Z_{i}+\sum_{i} \sum_{j} \lambda_{i j} \ln W_{i} \ln Z_{j}+\sum_{\text {Times }} \alpha_{T}+\sum_{\text {Firms }} \alpha_{F}
\end{aligned}
$$

Here, Aircraft Miles is the output $Y$ variable. This scale variable's coefficient, in a regression, tells us how unit costs would be influenced by simply repeating the activities of production more times. This gives us an indication of whether an industry becomes more efficient as firm size increases, i.e., whether it experiences positive "economies of scale." In CCT, seats and average flight distance (Stage) are held constant while Aircraft Miles, the scale variable, grows or shrinks. Effectively, this becomes departure count, ${ }^{3}$ the logical building block of "scale." The partial derivative of cost with respect to Available Seat Miles (ASMs) is also found here by using Aircraft Miles as a proxy for departures.

\footnotetext{
${ }^{3}$ Supposing the length of haul remains the same, a doubling in aircraft miles would by definition by synonymous with a doubling of departures. This may help readers come to terms with aircraft miles being used as a marker for firm size; it works because we are holding other factors equal.
} 
CCT estimate the above coefficients both as a full translog model, and a simplified model in which only the first-order coefficients are included. CCT report that "the coefficients for the simplified translog form... are remarkably similar to the first-order coefficients from the basic translog model." This suggests that second-order coefficients were either insignificant, or counterbalanced each other.

The interpretations of key coefficients for CCT were as follows:

- Aircraft Miles, $\quad$ Cost elasticity of density, identical flights, fixed network;

- Points served, the cost impact of spreading resources over an additional service point;

- Flight distance, $\quad$ cost of impact spreading the aircraft miles over fewer, longer flights.

$-\beta_{1}+\beta_{2}, \quad$ customary elasticity of scale, allowing geographic area to expand.

\subsection{Cost Model Literature - Returns to Scale, Density, Scope}

Positive economies of scope suggest that, even in a contestable market, firms will produce multiple products (or expand their networks) thanks to cross-product economies (Baumol, 1982). Without economies of scope, firms would not enter multiple cities or pursue hub networks. Most earlier papers have observed economies of density (decreasing unit costs as output increases in a given geographical area). They have also observed economies of scope, at least in the sense that one firm offering two products (or two travel routes) will be more efficient than two such firms covering that ground separately.

CCT find constant returns to scale in firm operations of the US airline industry. Economies of scope should be assumed in our environment; as said by Baumol, "Economies of scope are necessary for the existence of multiproduct competitive firms" (Baumol, 1982).

Gillen uses the formulation

$$
R T S_{C A L E}=\left[\frac{d \ln C}{d \ln [\text { Point Served }]}+\frac{d \ln C}{d \ln Y}\right]^{-1}
$$

where values above unity signify positive "returns" to scale. The reciprocal, cost elasticity of scale, would be less than unity. From their log-linear model, they find RTS of $1.35(t-$ stat $=$ 
2.1), meaning that RTS was significantly above unity, when firm dummies were included. With firm dummies omitted, there were no significant observed economies of scale. Canadian airline companies show increasing returns to density, when airline identities are included in regression, but no difference from unity if they are not included (Gillen, 1985).

Caves and Tretheway, writing in the period of the initial post-deregulation shakeout following 1978, believed that low costs of entry would facilitate equilibrium slowly. Their expectation was for any clear differences in technical efficiency among firms to abate over time, "as the regulatory era recedes into history," replaced by the apparently more thriving competitive market of today. Returns to scale would favor industrial consolidation, something that has in fact occurred dramatically since the CCT 1984 paper.

\section{Table 1 - Prior Literature First Order Approximated ${ }^{4}$ Cost Elasticities of Scale, Density, Fuel Price}

\begin{tabular}{|l|l|l|l|l|}
\hline & SCALE & DENSITY & FUEL PRICE & Years \\
\hline Caves (1984) & $.936(\mathrm{se} .065)$ & $.804(\mathrm{se} .034)$ & $.166(\mathrm{se} .001)$ & $1970-1981$ \\
\hline Gillen $(1985)^{5}$ & $.741(t=2.1)$ & $.568(t=4.8)$ & $.04(t=2.3)$ & $1964-1981$ \\
\hline Wei (2003) & $0.811(t=24.3)^{6}$ & N/A & $.240(t=7.21)$ & $1987-1998$ \\
\hline Chew (2005) & $1.012(\mathrm{se} .023)^{7}$ & Not done & $.1106(.0035)$ & $1994-2001$ \\
\hline
\end{tabular}

Positive economies of scope, if found, imply that airline hubs will emerge, according to simulation literature on the topic (Hendricks et al.,1999). Hub-spoke networks can be "a deterrent" to the entry of smaller carriers, due to structural revenue advantages (in essence, the revenue premium obtained by scope, as customers would prefer firms with greater network points, affording ease of shopping). In competitive markets, the increased cost of larger scope would apparently be justified by that revenue premium. While comparative

\footnotetext{
${ }^{4}$ While these are from full translog models, in which interactions matter, the first order coefficients (without interactions) can signify the cost elasticities at the sample means of the data (Wei, 2003).

${ }^{5}$ Gillen uses Canadian data. Log-linear model. The rest are U.S. only.

${ }^{6}$ This is returns to seat count (machine scale) within single aircraft types

${ }^{7}$ With local concavity imposed; for fleets.
} 
network costs are beyond the topic of their study, Hendricks says that a least-cost hub will be located where origin and destination distances are minimized across the cumulative traffic spectrum. This, too, explains how multiple hubs can arise in opposition to one another. Significantly, contestability and cost advantages are not simply analyzed at the flight leg level. Instead, airline costs represent networks that may compete from differing geographical perches (heterogeneity, as allowed by Berry, 1992). In competition, Hendricks finds the industry prone to monopoly due to economies of density. "Every city-pair market is effectively served by only one carrier, the one with a length advantage [across its transfer hub]..." Also, they note that while one hub carrier will tend to dominate, "nonhub networks raise average costs of service but may allow the carriers to price less aggressively," meaning they can expect another type of revenue premium.

Table 1 shows a compendium of previous airline cost studies in which returns to scale and density (and cost elasticity of fuel price) are obtained. While these may be expected to change over time, and particularly as regulatory or technological characteristics varied, a general CRS or light IRS characteristic is visible. CCT did not reject CRS in translog.

\subsection{Cost Model Specification Literature - Concavity Considerations}

The concavity of a cost function is one of the key conditions of its validity (Varian, 1984; Chambers, 1988). Concavity checks of the first order log-log cost function can be done directly by taking the second derivatives of the raw (non-logged) cost function. With the full translog-style equation however, it is noted that a concave function is always log concave. Therefore, by retaining logs, we can at least allow the possibility to reject (if the function is not log concave). Improvement on that basis can be measured.

A more complete way to check concavity of a translog style function is to check the AllenUzawa matrix of partial cost elasticities. Allen-partial matrix concavity implies Hessian matrix concavity (Featherstone, 2007). For the $i^{\text {th }}$ cross price elasticity at each observation, we have $\eta_{i j}=S_{j}+\frac{b_{i j}}{S_{i}}$, where $S_{i}$ is the cost share of input factor $i$. The equation also works where $i=j$ to get own-price Allen-Uzawa cost partial elasticities, from which the partials matrix can be made. This is done in the project to diagnose any concavity problems. 
A process has been developed to impose cost function concavity, if needed, in projects such as CCT and the present one (Ryan and Wales, 2000). This procedure was used recently by Chua, Kew and Yong, 2005; (hereafter, CKY). Earlier methods to impose global concavity will negate the flexibility of the translog form. Instead, CKY and Ryan / Wales impose local concavity. To do this, a particular data observation is designated the "normalization point." All its price, scale and state of nature variables are scaled to equal one; this ensures that the cost Hessian is negative semidefinite for that observation. By selecting the normalization point carefully, many or all of the observations' violations of concavity can be remedied. CKY detail several examples of cost studies whose results are questionable or reversed, following this procedure. The CKY method of imposing local concavity maintains the translog model's flexibility.

Using data for 10 airlines over the period 1994 to 2001, CKY present an enhancement and update of the earlier CCT cost estimation technique. CCT's cost function violates concavity at approximately half its observations. CKY were able to rehabilitate those data. They present their new study, which includes a translog cost function. They re-estimate the CCT cost function after imposing concavity, finding "material differences in scale economies" after doing so. Note that the CCT and CKY papers both use aggregate corporate data. In this paper, the concavity check recommended by CKY is used with consideration for their normalization remedy.

Further, modeling all normalizations and choosing the best one is a feasible extension that should prove simple and useful. Other concavity normalizations can impact flexibility of the cost function.

\subsection{Cost Model Specification Literature - Aggregation Considerations}

The second recent innovation subsequent to the CCT study is a method to dis-aggregate data when necessary. A recent translog cost estimation study provides a logical way to disaggregate operational numbers from firms into fleets (Basso and Jara-Diaz, 2005). It is noted that aggregate outputs $\tilde{y}_{h}$ are implicit functions of fleet outputs $Y$. Looking at operational metrics, Basso and Jara-diaz use ton-kilometeres $(T K)$ and average length of haul $(A L H)$ in $\tilde{Y}$. Then, 


$$
T K(Y)=\sum_{i j} y_{i j} \cdot d_{i j} \text { [where } d_{i j} \text { is distance of haul] }
$$

and

$$
\left.A L H(Y)=\sum_{i j} y_{i j} \bullet d_{i j} / \sum_{i j} y_{i j} \text {, [as opposed to }\left(\sum_{i j} y_{i j} \cdot d_{i j} / \sum_{i j} y_{i j}\right) \cdot d e p s_{t y p e} / \sum_{t=1}^{t y p e s} \text { deps }\right] \text {. }
$$

Basso and Jara-diaz explain that the above applies "where $d_{i j}$ is the distance travelled by flow $y_{i j}$ between origin $i$ and destination $j$. Therefore, even if the true (disaggregated) product vectors $Y^{A}, Y^{B}$ and $Y^{D}$ were unknown, $S C$ [economies of scale] could still be calculated correctly if the corresponding aggregates $\tilde{Y}\left(Y^{A}\right), \tilde{Y}\left(Y^{B}\right)$ and $\tilde{Y}\left(Y^{D}\right)$ were known, and an estimated cost function $\tilde{C}(\tilde{Y}, P S)$ was available..." 8 This is a method of rationalizing the distribution of aggregate metrics such as average length of haul by weighting it by product, in this case the ton-kilometer (the passenger-mile could work equivalently well, if we need a method to distribute such costs in a passenger study).

In similar recognition of aggregation problems, another recent study uses disaggregated, fleet level data ${ }^{9}$ to construct a translog operations cost model from Form 41 data (Wei and Hansen, 2003). This was done to study aircraft capital costs and the demand for certain aircraft types. Their use of Form 41's unaggregated direct operating cost data tables indicates some curiosity about fleet-level cost analysis, something expanded in the present project. I use the same data source tables as Wei and Hansen, together with a dis-aggregation technique similar to Basso, as will be described in the Model section for indirect costs.

While Form 41 includes detailed direct operating costs for all fleet types separately, data for indirect costs are not available by fleet. Indirect, or overhead, costs are only available at the firm level. To deal with this, Wei and Hansen confine their study to direct operating costs only, of fleets. But a full study of returns to scale (RTS) within the fleet context would require a total cost specification. By combining the methods of prior researchers, this paper

\footnotetext{
${ }^{8}$ Basso and Jara-Diaz (2005), p. 32

9 "Fleet level data" refers to a data source that specifically breaks out operational numbers by aircraft type within the firms. For example, it will give quarterly departures and gallons of fuel burned by AA MD-80s, 737s, etc. Otherwise, data is aggregated at the firm level (i.e., American Airlines as a whole).
} 
makes a special arrangement to pursue a disaggregated model, by synthetically disaggregating the indirect costs, and achieving a total cost measurement for the fleets, which is the dependent variable to be studied here.

\section{Model Specification}

\subsection{Model Overview}

The first goal of this paper is to build an effective base total cost model similar to prior literature. The CCT econometric model introduced earlier is still an effective framework if applied legitimately (as authors have done in various ways). The translog cost model (such as Eq. 5) is a well-tested practical method to approximate an unknown cost function with multiple input prices, operational styles, a time vector and firm dummy variables, nonlinearities, and interactions among the variables.

Ideally, that cost model would apply to fleets individually, to the extent that separate cost data sources exist. In this project, we have the right data ingredients to construct a cost study using the CCT framework at the fleet level, rather than the firm level. This allows analysis of fuel price effects on costs, as it impacts individual fleets within firms.

Fixed-effects model building is probably necessary, presuming firm-specific dummy variables are significant. A fixed effects model estimates coefficients for the variables, controlled for the time period and the entity (airline) reporting the costs. The model would then become more targeted, specific to each airline identity. By having fixed identities, the interpretation of coefficients (cost elasticities) refers to the experiences of individual firms whose parameters have changed over time, within the sample set. ("Within," as opposed to "between" firms).

Fleet-level direct operating costs are reported directly in the data. The assignment of indirect costs to flight operations is an inherently subjective endeavor that I must perform, because I lack the private data on fleet allocations of overhead costs. A researcher can perform this allocation nearly as well as the firms themselves, since we possess the firm-wide overhead cost data. These indirect costs such as advertising, insurance and corporate real estate are 
here weighted by aircraft miles. Thus, we have a source of Total Cost data for individual fleets ${ }^{10}$ :

$$
\text { Total Cost }=(\text { Direct Costs }+ \text { Pro-Rated Indirect Costs })
$$

This project uses Eq. 5 with the slight difference that Year is included among the $Z_{i}$ as a trend variable, rather than as dummy variables.

Because of the homogeneity of degree one restriction in input prices, (the $W_{i}$ ), we impose the following restrictions on (Eq. 5):

$$
\sum_{i} \beta_{i}=1 \quad \sum_{i} \gamma_{i j}=0 ; \quad \sum_{i} \rho_{i j}=0
$$

I estimate the first-order translog functions using SAS PROC SYSLIN; the translog equation is estimated using PROC MODEL, iterated SUR with restrictions entered imposed on the primal translog cost function.

Because the full translog cost function alone is prone to multicollinearity, it is standard practice to estimate it together with its dual expenditure-share functions (Ray, 1982). Two of the three inputs whose prices I include (Oil Price and Pilot Wages) have share equations included; the other share equation, Capital-Materials Price, need not be included because it is defined by the remaining two. The three equations (Total Cost and two of its input expenditure shares) are estimated together in an iterated Zellner seemingly unrelated regression (SUR) as a system of linear equations with correlated errors. The estimated parameters on the variables should be the maximum likelihood estimator (MLE) of their true values (CCT, 1984).

Expenditure shares are calculated as follows from the above translog cost primal:

$$
S_{i}=\frac{W_{i} X_{i}}{T C}=\left\lfloor\frac{\delta T C}{\delta W_{F}}\right\rfloor \frac{W_{F}}{T C}=\frac{\delta \ln T C}{\delta \ln W_{i}}=\beta_{i}+\sum_{j} \gamma_{i j} \ln W_{j}+\rho_{Y_{i}} \ln Y+\sum_{j} \lambda_{i j} \ln Z_{j}
$$

\footnotetext{
${ }^{10}$ Another method might have been to weight overhead costs by Available Seat Miles (ASMs), which might be useful in while accounting things like catering, which are sensitive to passenger count. Such accounting assignments are to some extent an arbitrary decision.
} 
A translog function is a second order Taylor series approximation of an unknown "true" cost function. Unlike with first-order translog, the elasticities of substitution between factors and/or production characteristics can vary in a so-called "flexible" functional form such as translog.

First-order translog assumes the production technology is homothetic, ${ }^{11}$ while translog does not. Still, this is not to say translog entirely captures the behavior of complex functions. For example, a generated CES function has been shown to be poorly approximated by translog.

In this notation, the intercept, firm dummies, output, input prices, and production characteristics are entered exactly as above. We also have symmetry since $\gamma_{i j}=\gamma_{j i}$. In the SAS code for this project, the symmetric variables were combined to conserve degrees of freedom. Given that this project uses time series data, severe multicollinearity may be a concern. Estimating the cost function alone as a single equation model would typically be vulnerable to multicollinearity (Ray, 1982). To avoid it, I exploit the features of duality to estimate the flexible cost function together with its input share equations, in a Zellner Seemingly Unrelated Regression (SUR) technique. Singularity is avoided by including only two of the three share equations in the model (fuel and pilots).

Unlike CCT 1984, I include time as a continuous variable so that time can be interacted with other items of interest (i.e., here I include it as one of the $Z_{i}$ ). Otherwise, the model is very similar to that earlier study, computationally. But keep in mind that the simultaneous study here of firm-level and fleet-level economies of scale is a major conceptual adjustment to their model.

Including factor share equations with the above will improve efficiency (Ray, 1982) by estimating the full dual system of equations, both cost and share equations together.

\footnotetext{
${ }^{11}$ Generally, $f(\mathrm{x})$ is homothetic if and only if it can be written as $f(\mathrm{x})=\Phi(g(x))$, where function $g($.$) is$ homogenous of degree 1 , and $\Phi$ is some transformation of the reals.
} 


\subsection{Model Key Point - Returns to Scope and/or Scale}

This model, like CCT, gives cost elasticities with respect to scale, density, or breadth/scope of service (the network points). Scale equals greater density over greater breadth (so those two separate coefficients can be summed to find RTS). I use the economies of network scope as described by Basso and Jara-Diaz to identify both RTS and RTD, as described in Table 2:

\section{Table 2 - Cost Elasticies of Scale}

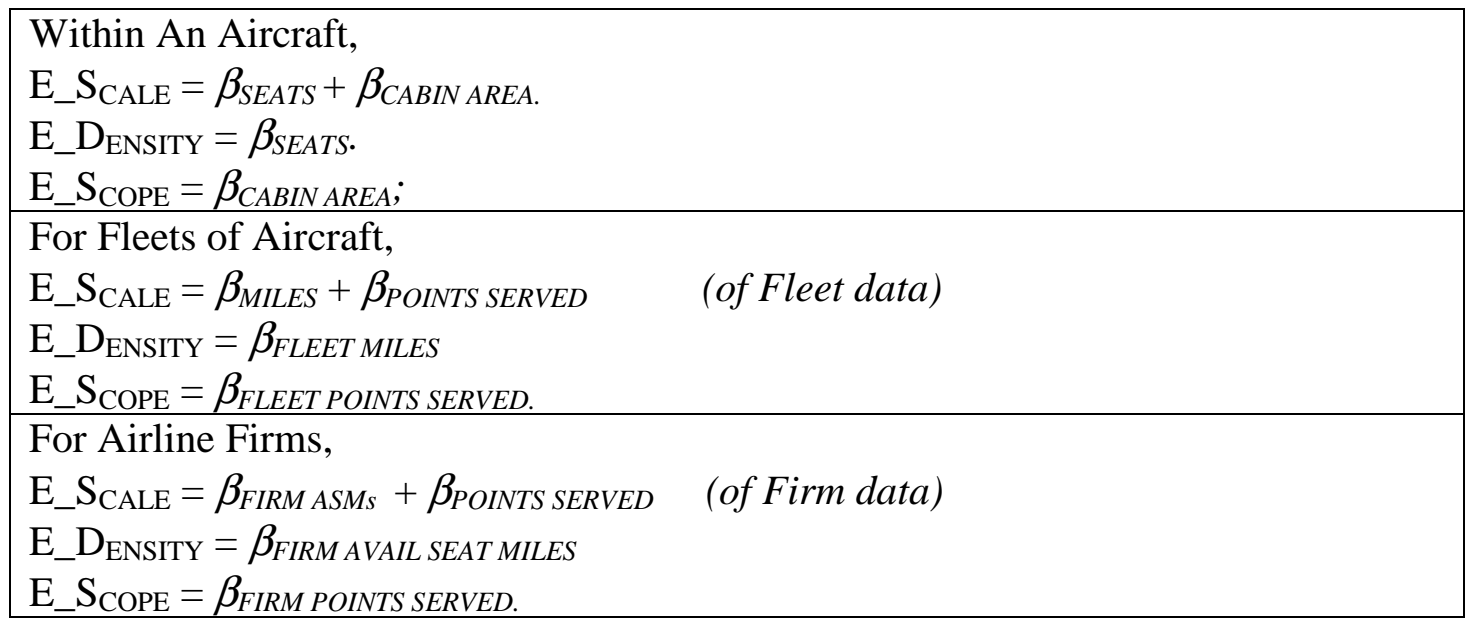

\subsection{Model Key Point - An Effort to Model Individual Flights, through Quarterly fleet Aggregates}

The Hicks Composite Commodity Theorem states that, "if the prices of a group of goods move in parallel, then that group of goods can be treated as a single good." This implies that it is desirable to model costs below the firm level. It is unlikely that firm-wide statistics will have the same cost elasticities of operational parameters, scale, and so on, as for its component fleets. Therefore, the firm-wide production process ought not to be treated as a single production function. Instead, using disaggregated data at the fleet level is more desirable. Meaningfully, equipment-specific data will ensure that the cost function does not mis-state the fleet level cost elasticities, which could occur without warning in the context of conventional firm-level aggregation, whose metrics are most often averaged by departure count. 
I use typical flights which are the average departure-weighted journey for each fleet. Fleets usually are directed to fairly narrow bands of operations, to capitalize on the relative strengths of each aircraft type. The mean distance per flight should have low variation within these fleets - certainly a lower variation than when attempting firm-wide analysis. By using quarterly data, a researcher is partway to an engineering-based cost model. Operationally similar flying should have similar costs, regardless of which particular cities are involved. This is because the laws of physics acting upon the aircraft are uniform, airports contestable, and a parameter for airway congestion can be included in the model.

Consider this hypothetical example in Table 3:

Table 3 - Example of Assignment-Driven Cost Efficiency Differential

\begin{tabular}{|l|l|l|l|l|l|}
\hline Aircraft Type & Seats & Stage & $\begin{array}{l}\text { Quarterly } \\
\text { Departures }\end{array}$ & $\begin{array}{l}\text { Quarterly } \\
\text { Operating Cost }\end{array}$ & $\begin{array}{l}\text { Cost per } \\
\text { Available } \\
\text { Seat Mile }\end{array}$ \\
\hline A319 & 120 & $375 \mathrm{mi}$ & 900 & $\$ 8$ million & $\$ 0.198$ \\
\hline A319 & 120 & $1,500 \mathrm{mi}$ & 360 & $\$ 9$ million & $\$ 0.139$ \\
\hline
\end{tabular}

This sort of data display can be used to isolate the frontier of operational feasibility. Firms that operate in a particular way would be expected to have particular costs by virtue of their schedule, and its interactions with other factors. The efficient frontier of production can best be found by examining fleet-level data. The vastly different Cost per Available Seat Mile $(C A S M)$ in the above pair could obscure the idea that both came from the same cost function. They may be equally efficient in terms of some underlying physical model. Their schedules largely dictate the average speed at which the fleets operate, which directly results in "outputs" such as ASMs that a model would expect can be produced by such fleets. We must take care that the costs are modeled realistically, noting that each fleet has a particular operational cost frontier.

The LHS of our regression will be the total cost of a subfleet's operations quarterly. This is reminiscent of a micro model of individual flights, in a Morrison/Swan engineering sense, as if the subfleet is iterating many identical average flights. Unfortunately, in the typical heterogeneous flight schedule, this assumption of flight uniformity is a gross simplification that is nonetheless required, since the cost data themselves are aggregates to some extent. It is hoped that mean values such as length of haul, divided by departures, will sufficiently model 
the micro flights from fleet data. Then the fleet average operational metrics could approximate the metrics of individual flights, upon which the laws of physics are likely to exert a role in terms of fuel and time requirements, and therefore cost.

This is a second-best method compared to actual flight modeling. We do not have data points for each of the roughly 10 million commercial passenger flights in the USA annually. The dataset compares fleet level data for several hundred fleets over the period 2000-2007 (comprising 2,660 usable observation points).

\section{Data and Empirical Strategy}

\subsection{Data Overview}

This project uses US DOT Form 41 data for the years 2000-2007, an eight-year panel of operational, financial, equipment and macro environment data. This is a large data source with high presumed reliability and completeness. Its metrics include quarterly data for each aircraft subfleet (such as Boeing 737-300, Airbus A319, etc) for each airline included in the sample. The sample includes most of the major players that comprise the US commercial market, as shown in Table 4.

Table 4 - Airlines in Sample, by Category

\begin{tabular}{|l|l|l|l|}
\hline \multirow{2}{*}{$\begin{array}{l}\text { Legacy } \\
\text { Carriers }\end{array}$} & Alaska & Continental & Northwest \\
\cline { 2 - 4 } & Aloha & Delta & United \\
\cline { 2 - 4 } & American & Hawaiian & US Airways \\
\cline { 2 - 4 } & America West & Midwest & \\
\hline
\end{tabular}

\begin{tabular}{|l|l|l|l|}
\hline Major Low- & AirTran & JetBlue & Southwest \\
\cline { 2 - 4 } Cost Carriers & ATA & Frontier & Spirit \\
\hline
\end{tabular}

\begin{tabular}{|l|l|l|l|}
\hline \multirow{2}{*}{$\begin{array}{l}\text { "Regional" } \\
\text { Airlines } \\
(<100 \text { Seats } \\
\text { aircraft })\end{array}$} & American Eagle & Pinnacle & SkyWest \\
\cline { 2 - 4 } & Comair & Mesa & Air Wisconsin \\
\cline { 2 - 4 } & ExpressJet & Mesaba & \\
\hline
\end{tabular}


This sample is diverse in equipment types, fleet counts, and styles of utilization. The data source is time series panel data with about 8000 observations, of which about 2500 are complete. The most commonly missing variable in dataset completeness has been network size (points served), for which certain values could not be obtained. Other values were manually corrected or deleted by the author if obviously false. Some included erratic numbers in connection with extremely small operational levels.

The Form 41 data source includes fleet specific direct operating costs (DC) such as pilot wages, fuel, etc, but does not include indirect costs (IC) like advertising and headquarters salaries. Indirect costs are only available at the aggregate corporate level (summing the fleets for each firm.) While corporate level Total Cost data are available on Form 41 Schedule P-12, subfleet level data must be simulated based on a linkage assuming that overhead costs $(=\mathrm{TC}$ - Direct Costs) are distributed uniformly across the firm's produced units. For now, we say overhead costs are distributed evenly across Aircraft Miles. This allows us to have realistic total operating costs (TC) for each fleet, in addition to the detailed operational data.

A representative data observation is described in Table 5, and the data are summarized in Table 6.

Table 5 - A Representative Data Observation from the Sample

\begin{tabular}{|l|l|l|l|l|l|l|l|l|l|}
\hline Airline & $\begin{array}{l}\text { Aircraft } \\
\text { Type }\end{array}$ & Quarter & Departures & $\begin{array}{l}\text { Seats } \\
\text { Available }\end{array}$ & $\begin{array}{l}\text { Avg } \\
\text { Length } \\
\text { of } \\
\text { Haul }\end{array}$ & $\begin{array}{l}\text { Seat } \\
\text { Capacity }\end{array}$ & $\begin{array}{l}\text { Available } \\
\text { Seat } \\
\text { Miles }\end{array}$ & $\begin{array}{l}\text { Gallons } \\
\text { of Fuel }\end{array}$ & $\begin{array}{l}\text { Crew } \\
\text { Costs }\end{array}$ \\
\hline $\begin{array}{l}\text { American } \\
\text { Airlines }\end{array}$ & MD-80 & Q2 2003 & 112,681 & $17,352,000$ & $856 \mathrm{mi}$ & 129 & $\begin{array}{l}12.94 \\
\text { Billion }\end{array}$ & $\begin{array}{l}260.5 \\
\text { Million }\end{array}$ & $\begin{array}{l}\$ 150.5 \\
\text { Million }\end{array}$ \\
\hline
\end{tabular}

Table 6 - Data summary, with Arithmetic and Weighted Means

\begin{tabular}{|l|l|l|l|l|l|}
\hline N=2660 & Mean & Std Dev & Minimum & Maximum & $\begin{array}{l}\text { Weighted Mean } \\
(A S M s)\end{array}$ \\
\hline FleetMi & $16,249,217$ & $16,466,421$ & 7,944 & $114,559,245$ & $31,684,496$ \\
\hline ACPoints & 34.444 & 24.651 & 2 & 132 & 43.037 \\
\hline ACSeats & 158.019 & 76.622 & 30 & 430 & 178.210 \\
\hline ACCabinArea & 124.168 & 80.460 & 27.195 & 380 & 143.502 \\
\hline ACFlightDist & 1357.54 & 1122.62 & 137.49 & 6570.79 & 1605.851 \\
\hline ACPilotWage & 481.70 & 348.37 & 2.01 & 9903.38 & 519.923 \\
\hline FuelPrice & 36.16 & 12.867 & 18.494 & 70.325 & 36.522 \\
\hline CapMPrice & 5293.75 & 2717.54 & 863.15 & 50530.4 & 5816.6 \\
\hline TechAge & 14.668 & 8.702 & 1 & 40 & 15.205 \\
\hline FirmASMs & 20355210153 & 14072344362 & 75669086 & 45920502143 & 27411965363 \\
\hline FirmPoints & 111.67 & 41.00 & 5 & 163 & 121.12 \\
\hline YearCount & 7.44 & 2.24 & 4 & 11 & 7.478 \\
\hline
\end{tabular}


The dataset was assembled in Microsoft Excel using raw data from the US Department of Transportation Bureau of Transportation Statistics online sources (www.bts.gov). Panels were merged into quarterly, fleet specific numbers for operations and direct costs of operation from Form 41 T2, T100. Lastly, the data were fed into SAS 9.1.3 for further data manipulation and econometrics processing.

\subsection{Model Regression Variables}

For both the first-order translog and translog cost models, the dependent variable was a calculation of Total Operating Costs. This was the sum of itemized direct costs and synthetically disaggregated indirect costs, by fleet, in 1997 dollars.

The 13 explanatory variables are:

- Fleet Aircraft Miles

- Fleet Network Points Quantity

- Seat Capacity

- Cabin Area
- Mean Flight Distance

- Cockpit Wage

- Oil Price

- Capital, Materials Price
- Equipment Design Age

- Firm Production

- Firm Network Size

- Year

(Firm identity - carrier-specific fixed effects.)

Cockpit wage is included in the regressions because, as noted by Wei and Hansen (2003), "pilots flying larger aircraft are paid more than those flying smaller aircraft, and these 'diseconomies' of pilot cost offset the 'technical' economies of aircraft size (...)" Therefore, I explicitly itemize the cost of the pilot factor in each fleet, from the item "Pilots and Copilots" of quarterly operational costs on Form 41. This allows us to treat pilot wages as essentially exogenous by entering the data. This removes bias from the coefficients on operational choices (aircraft types and statistics), removing potential bias of the estimators that were hiding pilot wage.

Is it reasonable to treat pilot wages as an exogenous correction of the model, but aircraft least rates as implicit? The rationale is the liquidity of aircraft, compared to the pools of airline pilots, which are fundamentally illiquid due primarily to unionization. But aircraft cannot unionize. From the data, similar airlines display stark wage disparities, both over time within firms, and among firms during constant time. This persistent illiquidity of factors is presumed not to exist with the capital stock. 
A key data omission to mention again is aircraft capital costs. I seek to omit aircraft costs by assuming that depreciation and rent parameters are economic equals.

$$
\text { Rent }=\text { Amortization = Economic Depreciation of Equipment } .
$$

While maintenance costs are explicitly available in Form 41, the purchase, ownership opportunity costs, or lease arrangements are not especially amenable to direct comparison. This becomes a serious problem if equipment cost items are only partially specified in the model, leading to problems with the adding-up restriction across many diverse firms with different equipment procurement or repair behaviors. Confusing the bookkeeping, a firm could try to maximize depreciation booked on such assets for tax purposes, or engage in accounting logic that deviates from economic realities. Rent may, consequently, be a problematic variable in our cost function. By instead focusing on operational parameters, as in the Morrison and Swan theory, we build equipment costs into the intercept of the equation. Or, in our case, it could form an amorphous "ready aircraft" commodity that we can build into Capital-Materials pricing. Firm identity variables might capture any remaining special nature of aircraft cost. This is based on the assumption of a liquid secondhand market for aircraft and continuous operating decisions on repairs vs. replacement of new aircraft.

\section{Estimation Results}

The cost model implies an industry-wide cost model and, therefore, an industry-wide production function. The industry's cost and production data are put into a model. The model yields estimated coefficients for the cost elasticities of various factors and styles of production. The degree of statistical confirmation of these estimates is reflected in the closeness of fitment of cost outcome estimation to real cost data - i.e., the $R^{2}$ for the estimated linear regressions.

By estimating a disaggregated model, the hope is that the most appropriate estimate takes place, which represents firm costs with respect to the type of machines employed. These machines represent, over time, variable decision-management units that might be subject to actual decisions or variations of production based on variables (such as seats per aircraft) dealt with here. If more seats are installed in an aircraft, this paper claims to model the cost 
elasticity - without, and then with second-order interactions - of that type of decision upon existing fleets. Therefore, the empirical model is historically meaningful, and also has something to say about the effects might be of actions taken by market actors. So, the model could reasonably be used for simulation.

The restricted model is:

$$
\begin{aligned}
& \ln [\text { Total Cost }]= \\
& \beta_{0}+\beta_{1} \ln [\text { Fleet Aircraft Miles }]+\beta_{2} \ln [\text { Fleet points served }]+\beta_{3}[\text { Seat Capacity }]+ \\
& \beta_{4} \ln [\text { Cabin Area }]+\beta_{5}[\text { Mean Flight Distance }]+\beta_{6}[\text { Cockpit Wage }]+ \\
& \beta_{7}[\text { Oil Price }]+\beta_{8}[\text { Capital-Materials Price }]+\beta_{9}[\text { Design Age }]+\beta_{10}[\text { Firm Quantity }]+ \\
& \beta_{11}[\text { Firm Scope }]+\beta_{12}[\text { Year }]+\beta_{i}[\text { firm identities }] .
\end{aligned}
$$

The less resricted, translog-style model is:

$$
\begin{aligned}
& \alpha_{0}+\alpha_{Y} \ln Y+\sum_{i} \beta_{i} \ln W_{i}+\sum_{i} \phi_{i} \ln Z_{i}+1 / 2 \delta_{Y Y}(\ln Y)^{2}+ \\
\ln [\text { Total Cost }]= & 1 / 2 \sum_{i} \sum_{j} \gamma_{i j} \ln W_{i} \ln W_{j}+1 / 2 \sum_{i} \sum_{j} \psi_{i j} \ln Z_{i} \ln Z_{j}+ \\
& \sum_{i} \rho_{Y} \ln Y \ln W_{i}+\sum_{i} \mu_{Y i} \ln Y \ln Z_{i}+\sum_{i} \sum_{j} \lambda_{i j} \ln W_{i} \ln Z_{j}+\sum_{\text {Firms }} \alpha_{F}
\end{aligned}
$$

(plus restrictions in Eq. 10) 


\subsection{First-order, Restricted Specification}

Table 7 - Subfleet First Order Total Cost Regression, 2000-2007 (1997 dollars)

\begin{tabular}{|c|c|c|c|c|c|c|c|c|}
\hline \multicolumn{9}{|l|}{$\log \_$TotalCost $=$} \\
\hline \multirow[b]{2}{*}{$\underline{\text { Variable }}$} & & \multicolumn{3}{|c|}{$\underline{\text { Fixed Effects }}$} & & \multicolumn{3}{|c|}{$\underline{\text { Statistics }}$} \\
\hline & & $\beta$ & S Error & $t$ & & \multicolumn{2}{|c|}{$\begin{array}{c}\text { Total } \\
\text { Observa } \\
\text { tions }\end{array}$} & 2660 \\
\hline Intercept & & -2.794 & .4156 & -6.72 & & \multicolumn{2}{|c|}{ Model DF } & 32 \\
\hline Log_ACMiles & & .8610 & .0069 & 124.89 & & \multicolumn{2}{|c|}{ Error DF } & 2628 \\
\hline Log_ACPointsSrv & & .1562 & .0103 & 15.16 & & \multicolumn{2}{|c|}{ SSE } & 71.4793 \\
\hline LogACSeats & & -.5126 & .0370 & -13.86 & & \multicolumn{2}{|c|}{ Root MSE } & .1649 \\
\hline Log_ACCabinArea & & .5944 & .0328 & 18.15 & & \multicolumn{2}{|c|}{$\mathbf{R}^{2}$} & .9753 \\
\hline Log_ACFlightDist & & -.0994 & .0130 & -7.64 & & \multicolumn{2}{|c|}{ Adjusted R ${ }^{2}$} & .9750 \\
\hline Log_ACPilotWage & & .0575 & .0084 & 6.84 & & \multicolumn{2}{|c|}{ Durbin-Watson } & .7102 \\
\hline Log_OilSpot & & .2037 & .0128 & 15.88 & & & & \\
\hline Log_C-MPrice & & .7387 & .0147 & 50.21 & & & & \\
\hline ACTechAge & & .0043 & .0004 & 9.68 & & & & \\
\hline Log_FirmASMs & & .0169 & .0193 & 0.88 & & & & \\
\hline Log_FirmPointsSrv & & .0006 & .0190 & $\mathbf{0 . 0 3}$ & & & & \\
\hline YearCount & & -.0009 & .0023 & -0.39 & & & & \\
\hline \multirow{2}{*}{\multicolumn{2}{|c|}{ Firm }} & \multicolumn{7}{|c|}{ Fixed Effects Firm Dummies (JetBlue as base) } \\
\hline & & \multirow[t]{2}{*}{$\beta$} & $t$ & Firm & $\beta$ & \multirow[t]{2}{*}{$t$} & \multirow{2}{*}{\multicolumn{2}{|c|}{ Firm }} \\
\hline$\beta$ & $t$ & & & & & & & \\
\hline $\mathbf{A A}$ & -.1458 & -2.65 & HP & -.0364 & -1.01 & $\mathbf{X E}$ & -.1479 & -2.71 \\
\hline DL & -.1365 & -2.61 & $\mathbf{T Z}$ & .3429 & 9.61 & $\mathbf{X J}$ & -.2083 & -2.98 \\
\hline NW & -.1174 & -2.43 & B6 & $\mathbf{0}$ & $\mathbf{0}$ & $\mathbf{Z W}$ & -.1667 & -2.66 \\
\hline $\mathbf{W N}$ & .0139 & $\mathbf{0 . 3 2}$ & FL & -.0047 & -0.13 & OO & -.1979 & -4.65 \\
\hline US & -.0150 & -0.35 & F9 & -.1118 & -1.26 & $\mathbf{O H}$ & .3390 & 6.07 \\
\hline UA & -.1023 & -1.90 & YV & -.1293 & -3.02 & MQ & -.1201 & -2.24 \\
\hline $\mathrm{CO}$ & -.1400 & -2.95 & $\mathbf{A S}$ & -.0957 & -2.55 & YX & -.1606 & -3.51 \\
\hline
\end{tabular}


The first order translog model appears to be a good specification (according to Figure 3) and enjoys easy interpretability. The coefficients represent fleet-level cost elasticities. Holding all else equal, this regression allows us to interpret the economies of density and scope, cost effects of increasing aircraft size, seat density, or oil costs and cockpit crew wages. While prohibiting interactions among the coefficients may be a bit simplistic, this regression does give some clear results that can be reported.

As shown in Table 8, cost elasticity of scale is approximately one (CRS is not rejected). In practical terms, this means that a firm could expand a particular fleet with constant unit costs. So, this means that firms have exploited available economies of scale, and attained efficient scale. This is not unexpected, considering the contestability of markets asserted.

The cost elasticity of aircraft scale is a bit new, but also well worth examination. The physical size of aircraft should engender greater efficiency, at least to a point. The coefficient on cabin area suggests that total costs increase with cabin area with an elasticity of approximately 0.594 (SE 0.33). This is so after controlling for seat count and operational style, including length of haul. Hence, aircraft have increasing returns to scale. See Table 8 (below) for this breakdown. Returns to scale in terms of the firm are measured to be insignificant. The coefficient on FirmASMs and FirmPointsSrv suggest that attributes of the overall firm do not directly impact costs accrued to the fleets, which is my topic of concern. Therefore the firm size, irrespective of fleets (which themselves have sizes), appears to carrly little or no predictive power over costs. We might say that there are no economies, positive or negative, associated with firm size after specifying fleet size. That's surprising, because the firms' fixed costs are allocated into the fleet costs, so we would expect economies of firm size to be visible. Also, no time trend is visible (all cost numbers are inflation-adjusted by CPIUrban). 
First Order Translog Fixed Effects Cost Function: Residuals

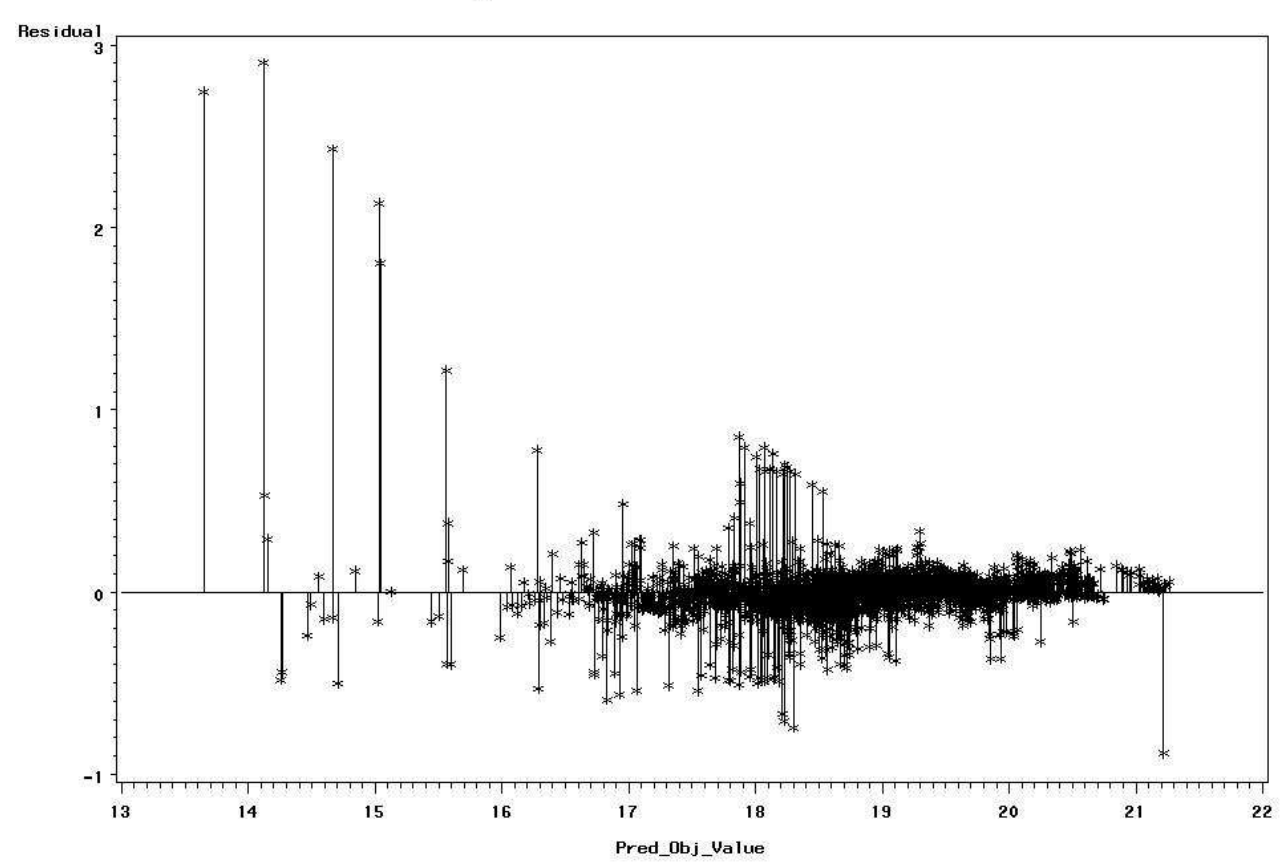

Figure 2 - First Order Restricted Fixed Effects: Residuals

Table 8 - Cost Elasticities of Scale and Scope ${ }^{12}$

\begin{tabular}{|l|l|l|}
\hline \multicolumn{3}{|c|}{ Fixed Effects Restricted Model: } \\
Cost Elasticities of Scale and Scope \\
\hline & Coeffs & SE \\
\hline Fleet Miles & 0.861 & .070 \\
\hline Fleet Scope & 0.156 & .010 \\
\hline$\Rightarrow$ Fleet Scale & $\Rightarrow 1.017$ & $\Rightarrow .080$ \\
\hline \multicolumn{3}{|c|}{} \\
\hline Aircraft Seats & -.513 & .037 \\
\hline Aircraft Scope & .594 & .033 \\
\hline$\Rightarrow$ Aircraft Scale & $\Rightarrow 0.082$ & $\Rightarrow .070$ \\
\hline
\end{tabular}

\footnotetext{
${ }^{12}$ Note: "Fleet Scale" refers to economies from more or wider operations of a given fleet; "Aircraft Scale" refers to larger or smaller aircraft.

${ }^{13}$ This appears to be a victim of model endogeneity. While increased seat count may be associated with less costly operators, any great increase in seat count should bring higher costs. Evidently, Cabin Area accounts for fleet scale while Seat Count is contingent upon it. The two do not interact properly for a scale measurement.
} 


\subsection{Translog Style Regression Results}

Table 9 - Subfleet Translog Style Total Cost Regression, 2000-2007 (1997 dollars)

\begin{tabular}{|c|c|c|c|c|c|c|c|c|c|}
\hline Equation & \multirow{2}{*}{$\begin{array}{l}\frac{N}{2660} \\
\end{array}$} & \multicolumn{2}{|c|}{ DF Model } & DF Error & SSE & \multicolumn{2}{|c|}{ Root MSE } & R-Square & D-Watson \\
\hline Log_TC & & \multicolumn{2}{|c|}{95.78} & 2564 & 29.2993 & \multicolumn{2}{|c|}{0.1069} & 0.9899 & 0.9508 \\
\hline ShareFuel & & \multicolumn{2}{|c|}{5.611} & 2564 & 1.6670 & \multicolumn{2}{|l|}{0.0251} & 0.8429 & 0.4728 \\
\hline $\begin{array}{l}\text { SharePilo } \\
\text { t }\end{array}$ & & \multicolumn{2}{|c|}{5.611} & 2564 & 0.5977 & 0.0150 & & 244 & 0.8730 \\
\hline log_Total & ost $=$ & & & & & & & & \\
\hline Vari & & $\beta$ & S Error & $t$ & & Variable & $\beta$ & S Error & $t$ \\
\hline Intercept & & 3.322 & 2.423 & 1.37 & & $(3 * 4)$ & 0.224 & 0.279 & 0.80 \\
\hline (1) $\log _{-} A C$ & iles & -1.043 & 0.122 & -8.53 & & $(3 * 5)$ & -0.983 & 0.083 & -11.78 \\
\hline (2) $\log _{-} A C$ & intsSrv & 2.477 & 0.181 & 13.70 & & $(3 * 6)$ & -0.005 & 0.002 & -2.06 \\
\hline (3) $\log A C S$ & & -6.768 & 0.751 & -9.02 & & $(3 * 7)$ & $\mathbf{0 . 0 3 0}$ & 0.004 & 6.99 \\
\hline (4) $\log _{-} A C$ & abinArea & 9.740 & 0.770 & 12.65 & & $(3 * 8)$ & 0.771 & 0.083 & 9.29 \\
\hline (5) $\log _{A} A C$ & ightDist & 0.146 & 0.305 & 0.48 & & $(3 * 9)$ & 0.013 & 0.004 & 3.17 \\
\hline (6) $\log _{-} A C$ & lotWage & 0.239 & 0.008 & 30.61 & & $(3 * 10)$ & 0.047 & 0.058 & 0.80 \\
\hline (7) $\log _{-} F u$ & Price & 0.269 & 0.014 & 18.77 & & $(3 * 11)$ & 0.075 & 0.087 & 0.86 \\
\hline (8) $\log _{-} C-I$ & Price & 0.492 & 0.015 & 32.07 & & $(3 * 12)$ & 0.006 & 0.011 & 0.61 \\
\hline (9) ACTech & & 0.005 & 0.012 & 0.41 & & $(4 * 5)$ & 1.048 & 0.089 & 11.78 \\
\hline (10) $\log _{-} F t$ & $n A S M s$ & 0.158 & 0.251 & 0.63 & & $(4 * 6)$ & 0.004 & 0.002 & 1.84 \\
\hline (11) $\log _{-} F t$ & nPtsSrv & -.640 & 0.362 & -1.77 & & $(4 * 7)$ & 0.043 & 0.004 & 10.38 \\
\hline (12) YearCo & & -.053 & 0.030 & -1.75 & & $(4 * 8)$ & -1.01 & 0.091 & -11.04 \\
\hline$\left(\log \_A C M i\right.$ & & 0.122 & 0.006 & 19.57 & & $(4 * 9)$ & -0.007 & 0.004 & -1.86 \\
\hline$\left(\log \_A C P o\right.$ & $t s S r v)^{2}$ & 0.266 & 0.021 & 12.57 & & $(4 * 10)$ & -0.106 & 0.056 & -1.91 \\
\hline (LogACSea & & 0.222 & 0.343 & 0.65 & & $(4 * 11)$ & -0.142 & 0.088 & -1.61 \\
\hline (ACCabinA & $a)^{2}$ & -0.269 & 0.279 & -0.97 & & $(4 * 12)$ & -0.008 & 0.010 & -0.88 \\
\hline$\left(\log \_A C F l\right.$ & $h t$ Dist $)^{2}$ & -0.051 & 0.044 & -1.15 & & $(5 * 6)$ & -0.003 & 0.001 & -0.34 \\
\hline$\left(\log _{-} A C P i l\right.$ & Wage $^{2}$ & 0.049 & 0.001 & 70.83 & & $(5 * 7)$ & 0.021 & 0.002 & 12.64 \\
\hline (Log_FuelP & $(c e)^{2}$ & 0.124 & 0.003 & 46.59 & & $(5 * 8)$ & 0.121 & 0.030 & 4.03 \\
\hline$\left(\log _{-} C-M P\right.$ & $c e)^{2}$ & -0.000 & 0.004 & -0.06 & & $(5 * 9)$ & 0.004 & 0.001 & 3.45 \\
\hline (ACTechAg & & 0.000 & 0.000 & 0.23 & & $(5 * 10)$ & 0.008 & 0.021 & 0.40 \\
\hline (Log_Firm & $M s)^{2}$ & -0.034 & 0.017 & -2.04 & & $(5 * 11)$ & -0.148 & 0.037 & -3.99 \\
\hline (Log_FirmI & $S r v)^{2}$ & -0.017 & 0.034 & -0.52 & & $(5 * 12)$ & -0.010 & 0.004 & -2.49 \\
\hline (YearCount & & -0.001 & 0.002 & -0.57 & & $(6 * 7)$ & 0.002 & 0.001 & 1.67 \\
\hline$(1 * 2)$ & & -0.162 & 0.011 & -14.92 & & $(6 * 8)$ & -0.047 & 0.001 & -40.66 \\
\hline$(1 * 3)$ & & 0.275 & 0.045 & 6.13 & & $(6 * 9)$ & -0.000 & 0.000 & -7.67 \\
\hline$(1 * 4)$ & & -0.422 & 0.044 & -9.65 & & $(6 * 10)$ & 0.002 & 0.001 & 3.56 \\
\hline$(1 * 5)$ & & -0.062 & 0.015 & -4.10 & & $(6 * 11)$ & -0.002 & 0.001 & -2.03 \\
\hline$(1 * 6)$ & & -0.006 & 0.001 & -10.84 & & $(6 * 12)$ & -0.002 & 0.000 & -13.01 \\
\hline$(1 * 7)$ & & -0.006 & 0.001 & -6.31 & & $(7 * 8)$ & -0.128 & 0.002 & -64.45 \\
\hline$(1 * 8)$ & & 0.012 & 0.000 & 11.98 & & $(7 * 9)$ & 0.001 & 0.000 & 20.49 \\
\hline$(1 * 9)$ & & -0.002 & 0.001 & -3.31 & & $(7 * 10)$ & 0.004 & 0.001 & 4.73 \\
\hline$(1 * 10)$ & & 0.046 & 0.009 & 5.21 & & $(7 * 11)$ & 0.002 & 0.001 & 1.39 \\
\hline$(1 * 11)$ & & 0.100 & 0.014 & 7.01 & & $(7 * 12)$ & -0.001 & 0.000 & -3.19 \\
\hline$(1 * 12)$ & & 0.006 & 0.002 & 2.97 & & $(8 * 9)$ & -0.001 & 0.001 & -0.53 \\
\hline$(2 * 3)$ & & -0.482 & 0.058 & -8.34 & & $(8 * 10)$ & 0.022 & 0.005 & 4.69 \\
\hline$(2 * 4)$ & & 0.650 & 0.057 & 11.39 & & $(8 * 11)$ & 0.139 & 0.022 & 6.44 \\
\hline$(2 * 5)$ & & 0.112 & 0.023 & 4.85 & & $(8 * 12)$ & 0.004 & 0.005 & 0.76 \\
\hline$(2 * 6)$ & & 0.006 & 0.001 & 6.98 & & $(9 * 10)$ & -0.001 & 0.001 & -1.38 \\
\hline$(2 * 7)$ & & 0.000 & 0.001 & 0.22 & & $(9 * 11)$ & -0.001 & 0.001 & -0.76 \\
\hline$(2 * 8)$ & & -0.150 & 0.014 & -10.86 & & $(9 * 12)$ & -0.000 & 0.000 & -2.84 \\
\hline$(2 * 9)$ & & 0.002 & 0.001 & 2.54 & & $(10 * 11)$ & -0.023 & 0.022 & -1.05 \\
\hline$(2 * 10)$ & & -0.016 & 0.012 & -1.33 & & $(10 * 12)$ & 0.001 & 0.003 & 0.43 \\
\hline$(2 * 11)$ & & -0.100 & 0.022 & -4.55 & & $(11 * 12)$ & 0.007 & 0.004 & 1.61 \\
\hline$(2 * 12)$ & & -0.009 & 0.003 & -2.79 & & & & & \\
\hline
\end{tabular}


Table 9 Continued - Subfleet Translog Style Total Cost Regression, 2000-2007 (1997 dollars)

\begin{tabular}{|c|c|c|c|c|c|c|c|c|}
\hline \multicolumn{9}{|c|}{ Fixed Effects Firm Dummies } \\
\hline Firm & $\beta$ & $t$ & Fir & $\beta$ & $t$ & Fir & $\beta$ & $t$ \\
\hline $\mathbf{A A}$ & 0.134 & 2.36 & $\mathbf{T Z}$ & 0.100 & 3.37 & $\mathbf{Z W}$ & -0.142 & -2.38 \\
\hline DL & 0.149 & 2.83 & FL & -0.019 & -0.63 & $\mathbf{O H}$ & 0.284 & 5.31 \\
\hline $\mathbf{U S}$ & 0.141 & 3.90 & F9 & 0.009 & 0.14 & MQ & -0.088 & -1.49 \\
\hline UA & 0.177 & 3.34 & YV & -0.110 & -2.38 & $\mathbf{A S}$ & 0.013 & 0.43 \\
\hline CO & 0.128 & 2.92 & $\mathbf{X E}$ & -0.108 & -1.93 & $\mathbf{Y X}$ & -0.175 & -4.27 \\
\hline HP & 0.034 & 1.19 & $\mathbf{X J}$ & -0.422 & -5.48 & NW & 0.116 & 2.54 \\
\hline B6 (base) & 0 & & OO & -0.224 & -4.85 & WN & -0.096 & -2.37 \\
\hline
\end{tabular}

Full Translog Cost Function: Residuals

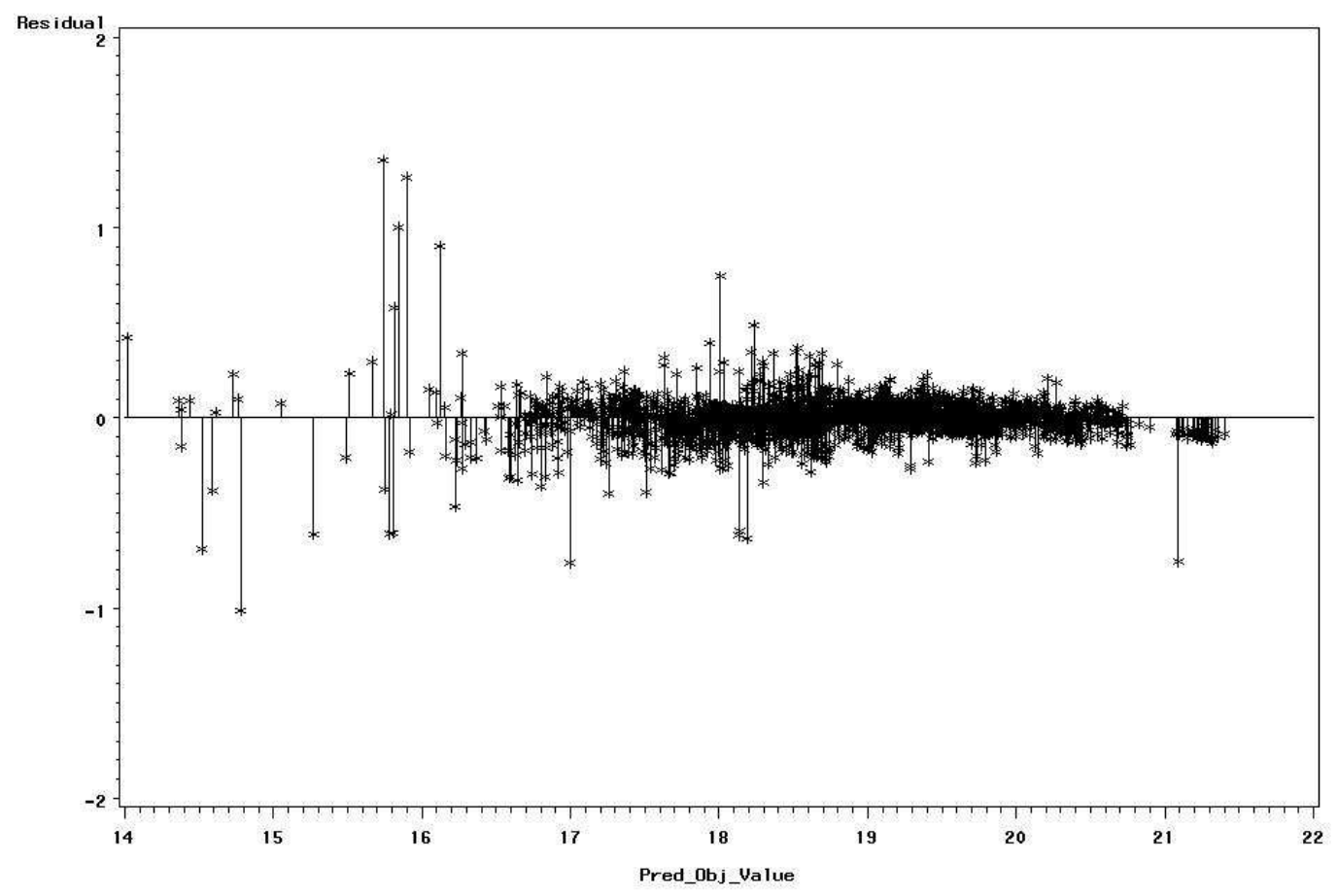

Figure 3 - Unrestricted Translog Style Regression: Residuals

Translog style regression results (in Table 9) can be at first difficult to interpret since secondorder effects (particularly with output) may obscure the first-order effects of the coefficients. For example, the inclusion of quadratics decomposes the first order interpretability we had in the first-order translog function. While CCT reported near-exact matches between first-order translog and first-order coefficients from the full translog regressions, it does not occur here.

The most interesting aspects of the translog results occur in observing the sign and interpretation of cross-elasticities in Table 9. For example, the cost share of fuel was 
positively correlated with older aircraft designs. Knowing this can lead to more realistic analysis and simulation.

The interaction of output (AC Miles) with inputs or characteristics also yielded interesting information. For bigger fleet outputs, the cost efficiency has been improving over time. With a coefficient of .006 (.002), as each year will have passed, growth of AC Miles will have had had a cost elasticity closer to unity. The cost economy available from growing a fleet has diminished over time.

\subsection{Returns to Scope, Scale}

\subsubsection{Fleets}

The initial first-order translog total cost model suggests that fleets have constant returns to fleet scale (AircraftMi), with cost elasticity of density (SE) of 0.861 (.007), and cost elasticity of fleet network size [scope] .156 (.010). Cost elasticity of total scale may be unity, and CRS cannot be rejected. The interpretation is, it appears that most firms operate their fleet at sizes large enough that further cost economies of scale are beyond reach.

As expected, the coefficient on mean Flight Distance is negative; as a flight distance doubles, costs will fall by $7.6 \%$. This is because Aircraft Miles have remained fixed, and as such, longer flights will be cheaper, with fewer departures, higher average speeds, and better productivity, as this model understands it.

Evidently, costs also increase with the design age of the fleets. Total costs rise by $0.43 \%$ (SE .0004) for each year older an aircraft fleet's mechanical design may be (these data were compiled by the author). The YearCount dummy (measuring annual changes in cost efficiency) is insignificant in itself in the TL style model, ignoring the issue of fleet design aging.

\subsubsection{Firms}

In the context of the fleet costs, the model does question whether firm total output quantity (ASMs) or firm geographic scope (PointsSrv, for the whole company) affect fleet costs. It appears that firm output quantity has no impact on a fleet's costs. 
The economy of scope (additional airports served) suggests it is quite cheap for firms to expand a given fleet's geographical "footprint," with an elasticity of only 0.156 (SE .01) for adding new network points while maintaining service quantity. This suggests an existing fleet could serve an additional city, or group of cities, rather cheaply. This, in turn, aids the argument that the overall market is contestable.

\subsubsection{Aircraft}

With respect to physical aircraft size, IRS are seen. The coefficient on ACCabinArea suggests that as we double aircraft interior space, costs rise by 59\%. This suggests positive economies of scale.

While the coefficient on ACSeats appears to suggest more seats result in actual cheaper flying, this is only an artifact of the context of fixed cabin size. This is probably because higher density seating configurations may be correlated with generally lower-cost firms, somehow missed despite our control for firm identities. Correspondingly, if a fleet within a firm were higher density, there may be unobserved traits about such a fleet that make it cheaper to operate (perhaps being an experimental subsidiary airline such as Metrojet, Song or TED, whose operations are included in this study under their corporate parents). This might explain, in part, why we see costs apparently falling as seat counts rise. An alternative model, with seating density in place of count, also produced this.

\subsection{Energy Cost Share and Response to Perturbation}

The sum of cost shares of Pilot Wages, Oil and Capital-Materials were constrained to unity in the regression using SUR in PROC SYSLIN (for the restricted model), and later in PROC MODEL (for the full TL style model). Their computed cost shares are 5.8\%, 20.4\% and $73.9 \%$ respectively. It should be noted again that the first-order translog functional form does not allow these cost shares to vary across the diversity of our sample, or even across time. A more flexible cost function specification allow them to move within their constraints.

The unrestricted translog style results show that energy cost share varies negatively with output scope and density; negatively with cabin area; and positively with flight distance. This suggests that larger aircraft have lower energy cost shares, which seems logical. 
In an unexpected energy shock, the returns to "green technology" rise would more steeply than anticipated, providing a windfall for those who invested in efficient machinery vs. their own forecasts. Conversely, those with the oldest technology will face an unexpected competitive problem. Typically, in a clearing market with risk neutral entities, we would expect that:

$$
\Sigma(\text { costs new / green technology })=\Sigma(\text { costs of old technology })
$$

\section{$\mathrm{E}[$ marginal rent on new aircraft $]=\mathrm{E}[$ added fuel cost in old aircraft $]$.}

Yet, we can see from our translog style results that apparently old machinery does not unduly penalize their operators. As oil prices rise, the coefficient on the interaction between log (Oil Price) and Tech Age was not significant in this study. Total costs of the airline are not exacerbated by the presence of older equipment, or minimized by the use of new equipment. Unexpected shifts in fuel cost seem to maintain the pure cost equivalence I assumed between new and old aircraft. However, it is worth remembering that older aircraft are more costly to run, according to the unrestricted model's TechAge coefficient.

The movements of oil prices are exogenous to the airline industry. But rolling expectations of oil prices may guide fleet procurement. From the data and the cost function measured here, we can describe what total costs would have been for the sample group of firms, between 2000-2007, at various fuel prices. This does not include feasibility conditions or capacity readjustments. A trend toward energy efficiency can be seen, as, although output has remained relatively constant, fuel burn has fallen and, hence, the industry is more robust to an oil price spike in 2007 than it was in 2000. The cost function is undefined at oil price $=\$ 0$, which is why the curve appears to join the origin. This graphic (Fig. 4) uses the translog style cost function from this project to extrapolate various costs for each observation in the data. The projected costs are then summed across the industry to get a total.

Similar to literature such as Thompson (2006), we can find energy cost share by Shephard's Lemma:

$$
F U E L=\frac{d(\text { TOTAL_COST })}{d(\text { FUEL_PRICE })}
$$




$$
\frac{d \ln (\text { Total Cost })}{d \ln (\text { Fuel Pr ice })}=\frac{d T C}{d F P} \bullet \frac{F P}{T C}=\varepsilon(\text { Cost : Fuel Pr ice })
$$

It follows that:

$$
\text { Share_Energy }=\frac{d \ln (\text { TOTAL_COST })}{d \ln (\text { FUEL_PRICE })} \text {. }
$$

For the first-order translog result in V.A, the fixed effects model result gives a cost / fuel price elasticity of 0.2037 (SE .0128). If oil prices increase $10 \%$, we would expect overall operating costs to increase by $2.04 \%$, for each fleet.

For the translog style function in 4.2, fuel share could be computed as follows:

$$
\frac{d \ln C}{d \ln w_{i}}=\beta_{i}+2 \beta_{i i}\left(\ln w_{i}\right)+\sum_{j=1}^{k} \beta_{i j} \ln w_{j}
$$

Using (14), we can plug in the estimated translog coefficients (5\% sig. threshold),

$$
\begin{gathered}
\frac{\partial \ln T C}{\partial \ln W_{F}}=S_{F}= \\
.113+.113 \cdot\left(\ln \_ \text {OilSpot }\right)-.005 \bullet\left(\ln \_ \text {ACMiles }\right)+-.046 \bullet\left(\ln \_ \text {PointsSrv }\right)+ \\
0 \bullet\left(\ln \_ \text {Seats }\right)-0.228 \cdot\left(\ln \_ \text {CabinArea }\right)+.104 \cdot\left(\ln \_ \text {Stage }\right)+ \\
-.007 \cdot\left(\ln \_ \text {CockpitWage }\right)-.027 \cdot\left(\ln \_ \text {CM_TPrice }\right)+0 \cdot(\text { TechAge })+ \\
0 \bullet\left(\ln \_ \text {FirmASMs }\right)+0 \cdot\left(\ln \_ \text {FirmPoints }\right)-0 \cdot(\text { YearCount }) .
\end{gathered}
$$

As has been noted by other authors, in the full translog model, each fleet of each firm had its own factor price elasticity. These could be aggregated by common output (ASMs) and then reported as industry-wide metrics (or as empirical means). This is done in Table 10.

Empirical means are reported as compared to first-order restricted translog results. Here, "empirical mean" of the full translog is meant as the cost elasticity of the input price, output level, or state of nature variable.

The derivative of $\log$ TotalCost with respect to each variable can be seen by re-using equation (16) and weighting the resulting cost elasticity by the $A S M$ production in that fleet, to get an aggregate industry statistic (an empirical mean). Figure 4 shows a useful projection of total industry costs as a function of oil prices, using the empirical model. 
Table 10 - Subfleet Translog Tot Cost Model vs. Restricted Model, 2000-2007 (1997 dollars)

\begin{tabular}{|c|c|c|c|c|}
\hline & \multicolumn{2}{|c|}{$\begin{array}{c}\text { First-Order, Restricted } \\
\text { Model }\end{array}$} & \multirow{2}{*}{$\begin{array}{l}\text { Full TL Style } \\
\text { Sample Mean } \\
\text { Elasticities }\end{array}$} & \multirow{2}{*}{$\begin{array}{l}\text { Full TL Style } \\
\text { Empirical, } \\
A S M \text {-weighted } \\
\text { Elasticities }\end{array}$} \\
\hline & (coeff) & (SE) & & \\
\hline Log_ACMiles & 0.861 & 0.007 & 0.972 & $\begin{array}{ll}1.018 \\
\end{array}$ \\
\hline Log_ACPointsSrv & 0.156 & 0.010 & 0.040 & 0.006 \\
\hline LogACSeats & -0.513 & 0.037 & -0.338 & -0.236 \\
\hline $\log _{A}$ ACCabinArea & 0.594 & 0.033 & 0.524 & 0.370 \\
\hline Log_ACFlightDist & -0.099 & 0.013 & -0.231 & -0.232 \\
\hline Log_ACPilotWage & 0.058 & 0.008 & 0.020 & 0.012 \\
\hline Log_OilSpot & 0.204 & 0.013 & 0.158 & 0.134 \\
\hline Log_C-MPrice & 0.739 & 0.015 & 0.571 & 0.532 \\
\hline ACTechAge & 0.004 & 0.000 & -0.027 & -0.029 \\
\hline $\log _{\text {FirmASMS }}$ & 0.017 & 0.019 & -0.008 & 0.001 \\
\hline Log_FirmPointsSrv & 0.001 & 0.019 & -0.102 & -0.088 \\
\hline YearCount & -0.001 & 0.002 & 0.003 & 0.006 \\
\hline
\end{tabular}

\section{Translog Industry Cost Extrapolation: Oil Price Shock}

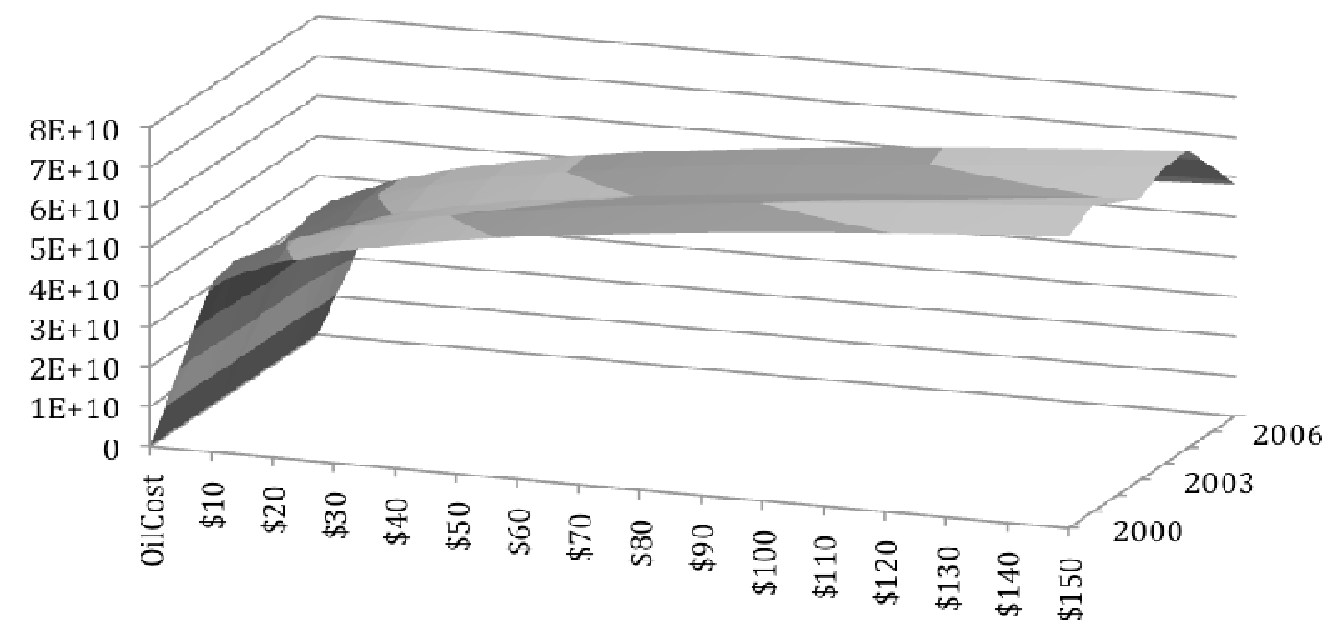

Figure 4 - Sample Group Simulated Total Costs, Varying with Oil Price / Bbl 


\section{Conclusion}

This paper has framed and measured a fleet-level cost model of production machines, as used by firms in the US airline industry. This project focuses primarily on the benefits of careful treatment of aggregation. Whereas other studies have used firm-level data only, or fleet-level data with indirect costs only, this work uses enjoys fleet-level data in a total-cost context, partially thanks to a synthetic disaggregation routine. This could be convenient for industrial simulation, because consumers pay total costs.

By placing all production (large and small aircraft, companies, and/or fleet sizes) over a panel of time periods, and putting them in one unified model, this project deploys the available analytical tools to model the industry's costs as they are affected by operational decisions. These decisions have effects across three levels of aggregation: (1) growth or shrinkage of an individual fleet, (2) the total firm as a whole; or (3) the nature of aircraft themselves, with respect to size, number of seats, and design age. These issues were all specified in the restricted and flexible TL models, and results were obtained.

In summary, the study finds that fleet economies of scale are not demonstrably different from CRS. However, there are economies of density, which has implications for regulators. Firm size, given the magnitude of fleet production, has no cost impact. Finally, bigger aircraft enjoy economies of scale, while increased density of seating is apparently associated with lower-cost producers, even while controlling for firm identity.

This paper examines economies of scale across three simultaneous levels of aggregation. Regarding fleets, each airline company uses a number of different aircraft types, as reported in the data. By modeling fleets (squads of like aircraft) as decision-management units (DMUs), aggregation bias is reduced. The practical relevance is also improved; a company manager or regulator, rather than contemplating a uniform expansion of overall output, will more often consider increasing or decreasing each fleet's activities independently. 
The cost function being modeled describes a hypothetical fleet of aircraft with parameters allowing typical situations - numbers of seats, total aircraft miles, number of airports, etc. The results should therefore be a forecast of total costs given reasonable inputs that are readily known at the outset of any planning process. These are used for a preliminary industry cost projection across fuel cost perturbations (Fig. 4).

When allowing flexibility of network size, CRS appeared to prevail at the fleet level. However, holding network size constant, economies of density were seen, in terms of additional aircraft miles. The fact this coefficient is being mitigated over time suggests economies of density may be fading away. However, at the aircraft-size level, continuing economies of airframe size were seen, as aircraft get larger. Firm-level returns to scale or density, often the subject of studies such as this, appeared largely irrelevant, after first accounting for the fleets.

Future research might find a compatible revenue function that can interface and provide a more complete industrial model with an econometric basis, to engage in further energy shock simulations.

\section{References}

Basso, L. J. and Jara-Dias, S. R. (2005) Calculation of Economies of Spatial Scope from Transport Cost Functions with Aggregate Output with an Application to the Airline Industry. Journal of Transport Economics and Policy, vol. 39, n. 1, pp 25-52.

Berry, S. T. (1992) Estimation of a Model of Entry in the Airline Industry. Econometrica, vol. 60, n. 4, pp. 889-917.

Caves, D. W., Christensen, L. R. and Tretheway, M. W. (1984) Economies of Density versus Economies of Scale: Why Trunk and Local Service Airline Costs Differ. Rand Journal of Economics, vol. 15, n. 4, pp. 471-489.

Chua, C. L., Kew, H. and Yong, J. S. (2005) Airline Code-share Alliances and Costs: Imposing Concavity on Translog Cost Function Estimation. Review of Industrial Organization, vol. 26, pp. 461-487.

Christensen, L. R., Jorgenson, D. W., and Lau, L. J. (1973) Transcendental Logarithmic Production Frontiers. The Review of Economics and Statistics, vol. 55, n. 1, pp. 28-45.

Christensen, L. R. (1980) Estimating The Impact of Rising Transportation Fuel Costs on the Competitive Position of New England Agriculture. Journal - Northeastern Agricultural Economics Council, vol. 9, n. 1, pp. 7-11.

Featherstone, A. and Christev, A. (2007) A Note on Allen-Uzawa Partial Elasticities of Substitution: The Case of the Translog Cost Function. IZA Discussion Paper, 2712 
Gillen, D. W., Oum, T. H. and Tretheway, M. W. (1985) Airline Cost and Performance: Implications for Public and Industry Policies. Vancouver: University of British Columbia.

Hamilton, J. H. and Thisse, J. F. (1993) Competitive Spatial Price Discrimination with Capacity Constraints. Transportation Science, vol. 27, n. 1, pp. 55-61.

Hendricks, K., Piccione, M. and Tan, G. (1999) Equilibria in Networks. Econometrica, vol. 67, n. 6, pp. 1407-1434.

Hurdle, G. J., Johnson, R. L., Joskow, A. S., Werden, G. J. and Williams, M. A. (1989) Concentration, Potential Entry, and Performance in the Airline Industry. Journal of Industrial Economics, vol. 38, n. 2, pp. 119-139.

Morrison, S. A. (1984) An Economic Analysis of Aircraft Design. Journal of Transport Economics and Policy, May, pp. 123-143.

Ray, S. (1982) A Translog Cost Function Analysis of U.S. Agriculture, 1939-77. American Journal of Agricultural Economics, August, pp. 490-498.

Ryan, D. L. and Wales, T. J., (1999) Imposing Local Concavity in the Translog and Generalized Leontief Cost Functions. Economics Letters, vol. 67, pp. 253-260.

Shephard, R. W. (1970) Theory of Cost and Production Functions. Princeton: Princeton University Press.

Sickles, R. C., Good, D., and Johnson, R. L. (1986) Allocative Distortions and the Regulatory Transition of the U.S. Airline Industry. Journal of Econometrics, vol. 33, pp. 143-163.

Swan, W. M. and Adler, N. (2006) Aircraft trip cost parameters: A function of stage length and seat capacity. Transportation Research Part E, vol. 42, pp. 105-115.

Thompson, H. (2006) The applied theory of energy substitution in production. Energy Economics, vol. 28 , pp. 410-425.

Wei, W. and Hansen, M. (2003) Cost Economics of Aircraft Size. Journal of Transport Economics and Policy, vol. 37, n. 2, pp. 279-296. 